\title{
Effects of thickness and background on the masking ability of high -trasnlucent zirconias
}

\author{
Young-Gon Kim, Ji-Hye Jung, Hyun-Jun Kong, Yu-Lee Kim* \\ Department of Prosthodontics, College of Dentistry, Wonkwang University, Iksan, Republic of Korea
}

\begin{abstract}
Purpose: The purpose of this study was to compare and evaluate the masking ability of three types of high translucent zirconia according to the various thicknesses and backgrounds. Materials and Methods: Using three types of high-translucency zirconia (Ceramill zolid fx white, Ceramill zolid ht+ white, Ceramill zolid ht+ preshade A2), 10 cylindrical specimens were fabricated in $10 \mathrm{~mm}$ diameter and each with four thicknesses $(0.6 \mathrm{~mm}, 1.0 \mathrm{~mm}, 1.5 \mathrm{~mm}, 2.0 \mathrm{~mm})$, respectively by CAD/CAM method. The background was $10 \mathrm{~mm}$ in diameter and $10 \mathrm{~mm}$ in thickness. A1, A2, A3 flowable resin backgrounds, blue-colored core resin background, and $\mathrm{Ni}-\mathrm{Cr}$ alloy background were prepared, and black, white backgrounds provided by the spectrophotometer manufacturer ( $x$-rite, Koblach, Austria) were used. zirconia specimens and the background specimen were stacked to measure $L$, a*, $b^{*}$ with Spectrophotometer (Color i5, x-rite, Koblach, Austria) and the $\Delta \mathrm{E}$ value with the other background is calculated. The Calculated mean $\Delta \mathrm{E}$ values were compared based on perceptibility threshold 1.0 and acceptability threshold 3.7. Nonparametric tests such as Kruskal-Wallis test were performed to verify statistical significance $(\alpha=0.05)$. Results: There was a significant difference in the mean $\Delta \mathrm{E}$ value according to the zirconia type, background and thickness change $(P=0.000)$. Conclusion: According to the results of this study, the pre-colored high-translucent zirconia can obtain the desired zirconia shade when it is restored on teeth, composite resins, and abutments except for the blue resin core. (J Dent Rehabil Appl Sci 2021;37(4):199-208)
\end{abstract}

Key words: zirconia; masking ability; translucency; thickness; background; spectrophotometry

\begin{abstract}
서론
자연치아는 색조뿐 아니라 반투명도, 형광성 등의 다 양한 광학적 특성을 가진다. ${ }^{1}$ 이런 특성을 재현하기 위해 심미 수복물이 개발되어 왔으며 이 중 도재 수복물은 심 미 수복물로 오랫동안 사용되어왔지만 약한 강도가 단 점으로 지적되어왔다. 도재의 취성을 보완하기 위해 우 수한 기계적 강도를 가지는 금속에 접합하여 금속-도재 수복물이 사용되었지만 금속-도재 수복물은 빛 투과가 되지 않아 자연치의 반투명도를 재현하기 어려우며 치은 퇴축으로 하부 금속의 색이 비칠 수 있는 등 도재 수복물
\end{abstract}

*Correspondence to: Yu-Lee Kim

Professor, Department of Prosthodontics, College of Dentistry, Wonkwang University, 895 Muwang-ro, Iksan, 54538, Republic of Korea

Tel: +82-63-859-2937, Fax: +82-63-857-4002, E-mail: pro11@wku.ac.kr

Received: July 30, 2021/Last Revision: August 23, 2021/Accepted: October 2,
에 비해 심미적인 단점이 존재한다.,3

도재 수복물의 반투명도는 자연치와 유사한 반투명도 를 부여할 수 있어 심미적 장점이 될 수 있으나 특정 환 경에서는 단점으로 작용할 수 있다. ${ }^{4,5}$ 예를 들어 변색치, 레진 및 아말감 코어, 임플란트 지대주 등이 도재 수복물 하방에 존재하는 경우 하부 색조가 비치면서 술자가 원 하는 목표 색조 설정에 어려움을 겪게 된다. ${ }^{6,7}$ 반대로 하 부 구조 색조를 가리기 위하여 불투명도가 높은 도재를 선택하면 자연치의 심미 재현이 어려울 수 있다. 따라서 수복물의 목표 색상을 얻기 위해 수복물의 반투명도와 하부 색상 차단 능력의 적절한 조화가 중요하다.

CopyrightC 2021 The Korean Academy of Stomatognathic Function and Occlusion. (c) It is identical to Creative Commons Non-Commercial License. 
지르코니아의 반투명도는 빛의 투과, 반사, 산란에 따 라 달라진다. ${ }^{8}$ 빛의 투과량이 많을수록 반투명도가 증가 하며 산란량이 증가하면 불투명도가 증가한다. ${ }^{8}$ 이전 연 구들에 의하면 지르코니아 코어의 두께가 증가함에 따 라 반투명도는 감소한다. Wang 등 은 지르코니아의 반 투명도는 제조사와 두께에 따라 달라지며 도재보다 지르 코니아가 두께 변화에 덜 민감하다고 보고하였다. Kanchanavasita 등 $^{10}$ 은 지르코니아의 평균 대비율 값이 지르 코니아 브랜드와 두께에 따라 달라진다고 보고하였다. Sulaiman 등 $^{11}$ 도 지르코니아 브랜드에 따라 다른 반투명 도를 보이며 두께에 영향을 받는다고 보고하였다.

지르코니아는 치과용으로 사용되는 도재 중 가장 낮은 반투명도를 가지는 것으로 보고되었다. ${ }^{12}$ 이와 같은 지르 코니아의 낮은 반투명도를 개선하기 위해 이전에는 반투 명도가 높은 비니어 도재와 같이 사용하였으나 비니어 도재 탈락 및 파절 등의 문제점이 있었으며 이를 개선하 기 위해 이트리아(Yttria) 등을 첨가하여 반투명도를 높 인 고투명도 단일 지르코니아가 개발되기 시작하였으며 만족할만한 기계적 강도를 보였다. ${ }^{13}$ 지르코니아의 반투 명도는 제조사 및 입자 크기와 함량, 이트리아(Yttria) 함 량, 착색 및 소성 방법 등에 따라 영향을 받는다. ${ }^{12-14}$ 또한 도재의 두께가 증가함에 따라 반투명도가 감소하며 지 르코니아는 도재에 비하여 두께 변화에 따른 반투명도의 변화가 적게 나타난다고 보고되었다. ${ }^{15}$

수복물의 차단 효과를 평가하기 위해 사용되는 색측정 시스템은 CIELa*b* 시스템이다. 이 시스템에서, 색공간 에서 특정 색조의 위치는 세 좌표로 정의된다. ${ }^{16} \mathrm{~L}$ 은 물체 의 명도를 나타내며 $\mathrm{a}^{*}$ 는 적/록 축, $\mathrm{b}$ *는 황/청 축을 나 타낸다. 계산된 $\Delta \mathrm{E}$ 값을 바탕으로 사람의 눈으로 관찰 되는 색조 차이의 한계값을 설정하기 위하여 허용 한계 및 인지 한계라는 개념이 소개되었다. 인지 한계보다 $\Delta \mathrm{E}$ 의 값이 크다면 시각적으로 색차를 판단할 수 있다는 것 을 의미하며 허용 한계보다 $\Delta \mathrm{E}$ 값이 크다면 심미적으로 받아들여질 수 없는 색상 차이가 존재함을 의미한다. 허 용 한계 및 인지 한계는 많은 문헌에서 다양한 값으로 제 시되었는데, 본 연구에서는 $\Delta \mathrm{E}$ 의 인지 한계는 1.0 , 허용 한계는 3.7을 기준으로 설정하였다. ${ }^{17-20}$

고투명도 지르코니아 코어의 두께에 따른 색조 차단 효과에 대한 연구들이 다수 보고되었지만, ${ }^{7,21}$ 사용된 하 부 배경이 복합 레진이나 검정색, 흰색에 국한되어 있으 며 임상에서 사용하는 코어 레진이나 금속 재료 등에 대 한 색조 차단 효과 연구는 부족하였다. 따라서 본 연구의
목적은 고투명도 지르코니아의 두께 및 배경에 따른 색 조 차단 효과를 비교, 평가하고자 하는 것이다. 귀무 가 설은 고투명도 지르코니아의 종류, 두께 및 하부 배경에 따라 색조 차단 효과의 차이가 없다는 것이다.

\section{연구 재료 및 방법}

고투명도 pre-stained 지르코니아 블록인 Ceramill zolid ht+ preshade A2; HP (Amann Girrbach AG, Koblach, Austria), 고투명도 흰색 지르코니아 블록인 Ceramill zolid ht+ white; HW (Amann Girrbach AG) 및 고투명도 흰색 지르코니아 블록인 Ceramill zolid $\mathrm{fx}$ white; FW (Amann Girrbach AG) 총 3가지 종류의 지 르코니아 블록을 사용하였다(Table 1). FW는 HW의 반 투명도보다 약 $10 \%$ 높다고 제조사에서 표기하고 있다. $\mathrm{HP}$ 는 $\mathrm{HW}$ 및 $\mathrm{FW}$ 와 달리 치아 색조를 부여하는 stain 처리가 되어 있다. 지르코니아 시편은 직경 $10 \mathrm{~mm}$ 의 원 통형으로 제작하였으며, 두께는 $0.6 \mathrm{~mm}, 1.0 \mathrm{~mm}, 1.5$ $\mathrm{mm}, 2.0 \mathrm{~mm}$ 네 가지 군으로 분류하여 stl 파일을 제작 한 뒤 CAD/CAM 가공 기계(Ceramill motion 2, Amann Girrbach)로 각 두께 군마다 10개씩 시편을 제작하였다 (Fig. 1). 모든 지르코니아 시편을 소성로(Ceramill therm, Amann Girrbach)에서 $20^{\circ} \mathrm{C}$ 에서 $1450^{\circ} \mathrm{C}$ 까지 온도를 상 승시킨 후 $1450^{\circ} \mathrm{C}$ 에서 2 시간 동안 온도를 유지한 후 소 성하여 완성하였다. 실험 전 시편을 초음파 세척기에서 20 초간 세척한 후 압축 공기로 건조하였다.

하부 배경은 A1, A2, A3 색조의 유동성 레진(Filtek Z350 XT flowable, 3M, Minnesota, USA) (이하 A1, A2, $\mathrm{A} 3$ 레진 하부 배경), blue 색조의 코어 레진(Luxacore Z smartmix dual, DMG, Hambrug, Germany) (이하 청색 하부 배경), $\mathrm{Ni}-\mathrm{Cr}$ 합금(이하 금속 하부 배경) 및 추가로 분광 광도계 제조사(Amann Girrbach)에서 제공하는 흰 색 및 검정색 하부 배경을 사용하였다(Fig. 2).

하부 배경 시편 제작을 위해 실리콘 인상재(EXAFLEX putty, GC, Tokyo, Japan)로 직경 $10 \mathrm{~mm}$, 깊이 10 $\mathrm{mm}$ 의 원통형 틀을 형성하였다. A1, A2, A3 유동성 레진 및 청색의 코어 레진을 틀 내로 1 회에 $2 \mathrm{~mm}$ 이내의 높이 로 충전하여 20초간 광중합하여 5 - 6 회 적층법으로 $\mathrm{A} 1$, A2, A3 레진 및 청색 하부 배경을 제작하였고, 왁스를 틀 내로 주입한 뒤 Ni-Cr 합금으로 주조하여 금속 하부 배 경을 제작하였다. 실험 전 하부 배경을 초음파 세척기에 서 20초간 세척한 후 압축 공기로 건조하였다. 
Table 1. Materials of high-translucent zirconia used in this study

\begin{tabular}{|c|c|c|c|}
\hline Product name & Code & Shade & Composition(\%) \\
\hline Ceramill zolid ht+ preshade & HP & $\mathrm{A} 2$ & $\begin{array}{c}\mathrm{ZrO}_{2}+\mathrm{HfO}_{2}+\mathrm{Y}_{2} \mathrm{O}_{3} \geq 99 \\
\mathrm{Y}_{2} \mathrm{O}_{3}=6.0-7.0 \\
\mathrm{HfO}_{2} \leq 5 \\
\mathrm{Al}_{2} \mathrm{O}_{3} \leq 0.5 \\
\text { other oxides } \leq 1\end{array}$ \\
\hline Ceramill zolid ht+ white & HW & White & $\begin{array}{c}\mathrm{ZrO}_{2}+\mathrm{HfO}_{2}+\mathrm{Y}_{2} \mathrm{O}_{3} \geq 99 \\
\mathrm{Y}_{2} \mathrm{O}_{3}=6.7-7.2 \\
\mathrm{HfO}_{2} \leq 5 \\
\mathrm{Al}_{2} \mathrm{O}_{3} \leq 0.5 \\
\text { other oxides } \leq 1\end{array}$ \\
\hline Ceramill zolid fx white & $\mathrm{FW}$ & White & $\begin{array}{c}\mathrm{ZrO}_{2}+\mathrm{HfO}_{2}+\mathrm{Y}_{2} \mathrm{O}_{3} \geq 99 \\
\mathrm{Y}_{2} \mathrm{O}_{3}=8.5-9.5 \\
\mathrm{HfO}_{2} \leq 5 \\
\mathrm{Al}_{2} \mathrm{O}_{3} \leq 0.5 \\
\text { other oxides } \leq 1\end{array}$ \\
\hline
\end{tabular}

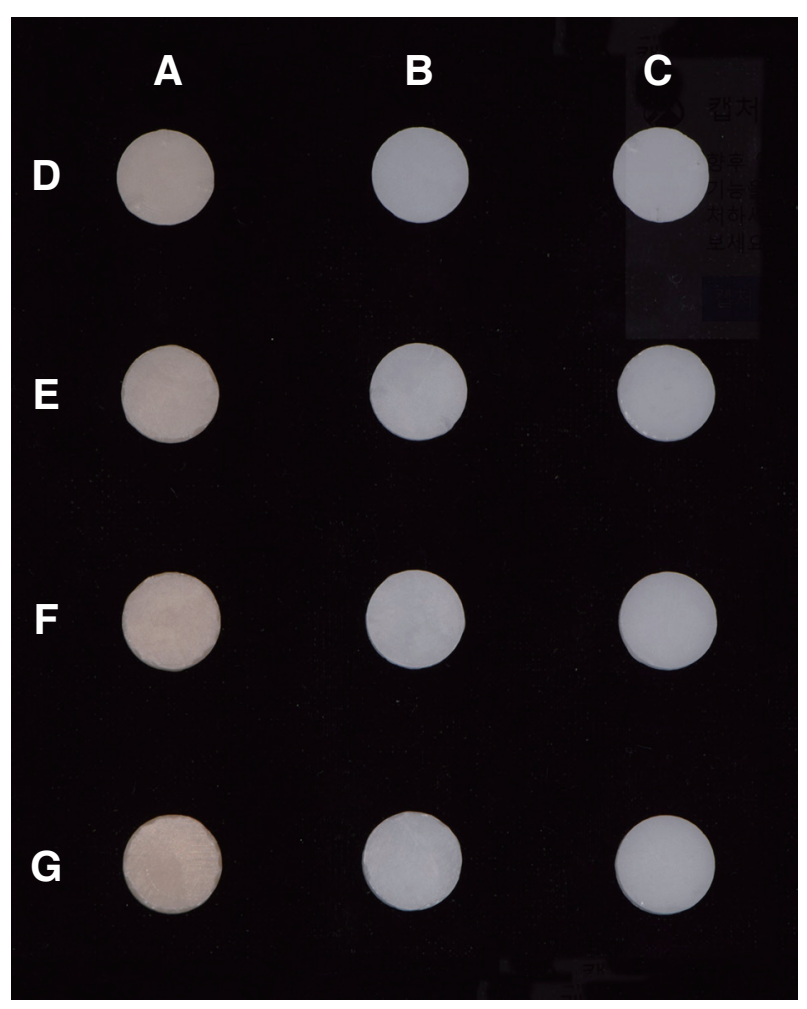

Fig. 1. Zirconia specimens used in this study. (A) Ceramill zolid ht+ preshade A2, (B) Ceramill zolid ht+ white, (C) Ceramill zolid fx white, (D) $0.6 \mathrm{~mm}$ thickness, (E) $1.0 \mathrm{~mm}$ thickness, (F) $1.5 \mathrm{~mm}$ thickness, (G) $2.0 \mathrm{~mm}$ thickness.

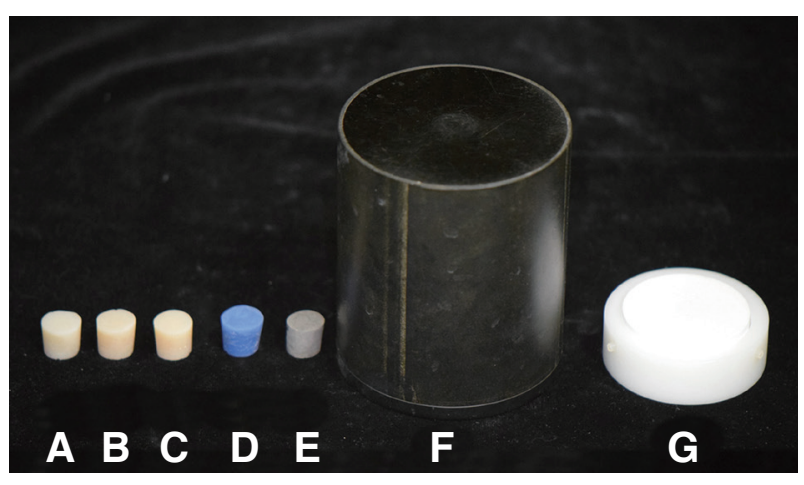

Fig. 2. Backgrounds used in this study. (A) A1 flowable resin, (B) A2 flowable resin, (C) A3 flowable resin, (D) Luxacore $\mathrm{Z}$ smartmix dual (Blue), (E) Ni-Cr alloy (Metal), (F) black, (G) white.

분광 광도계(Color i5, x-rite, Michigan, USA)로 L, a*, $\mathrm{b}^{*}$ 측정 및 $\Delta \mathrm{E}$ 값을 계산하였다(Fig. 3). 측정된 $\mathrm{L}, \mathrm{a}^{*}, \mathrm{~b}^{*}$ 값으로 두 물체 간의 색차를 의미하는 $\Delta \mathrm{E}$ 값을 다음 공 식에 따라 산출하였다. ${ }^{4}$

$$
\begin{aligned}
& \Delta \mathrm{E}_{12}=\left[\left(\mathrm{L}_{2}-\mathrm{L}_{1}\right)^{2}+\left(\mathrm{a}_{2}{ }_{2}-\mathrm{a}_{1}\right)^{2}+\left(\mathrm{b}_{2}{ }_{2}-\mathrm{b}_{1}\right)^{2}\right]^{1 / 2} \\
& (\Delta \mathrm{E}: \text { 색차, } \mathrm{L}: \text { 명도, } \mathrm{a} \text { : 적-록 값, } \mathrm{b} \text { : 황-청 값 })
\end{aligned}
$$




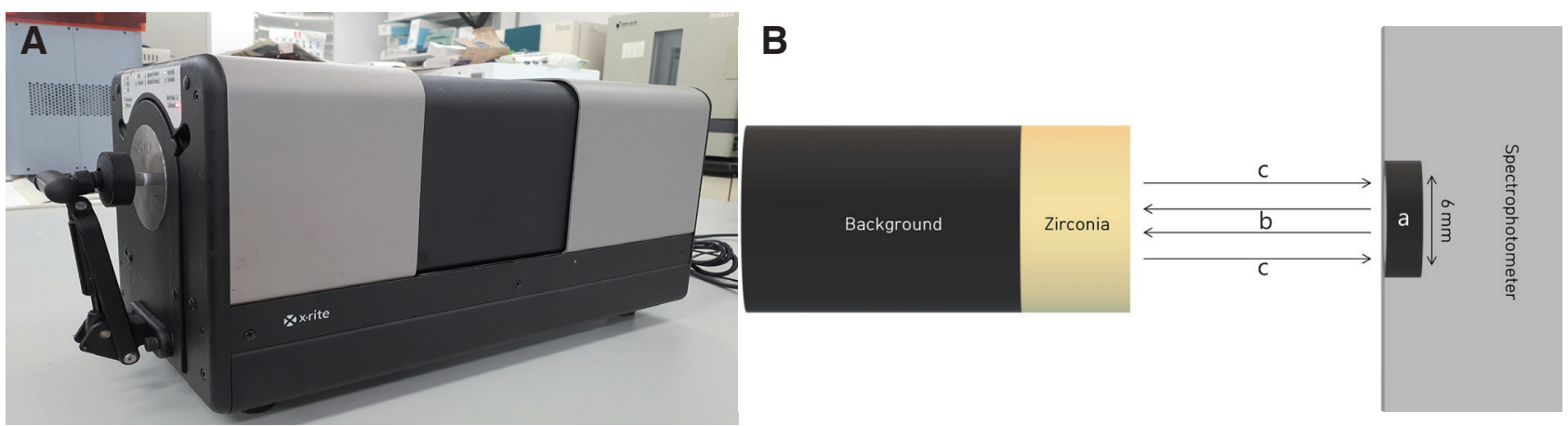

Fig. 3. Measurement CIELa*b*. (A) Spectrophotometer Color i5 (x-rite, Michigan, USA) used in this study, (B) Diagram for measuring CIELa*b* by using spectrophotometer. a: $6 \mathrm{~mm}$ diameter aperture, b: D65, c: light reflection.

Color i5 (x-rite) 분광 광도계를 본 실험 색조 측정에 사용하였다. 모든 측정에는 D65 표준 광선을 사용하였 으며 측정 전 제조사에서 제공하는 검정색 및 흰색 표준 배경으로 보정하였다. 측정 방법은 분광 광도계의 표준 광선이 조사되는 $6 \mathrm{~mm}$ 직경의 구경에 지르코니아 시편 의 중앙부를 빈틈없이 위치시키고 지르코니아 시편 하방 에 하부 배경을 접착제없이 밀착시켰다. 측정은 D65 표 준 광선을 네 번 조사하여 총 2회 시행하면 Color i5 소프 트웨어 프로그램인 Color iControl (x-rite)에 L, a*, b* 값 이 소수점 둘째 자리까지 표시되었다. HP는 A2 레진 하 부 배경에서 측정한 $\mathrm{L}, \mathrm{a}^{*}, \mathrm{~b}$ 을, $\mathrm{HW}$ 와 $\mathrm{FW}$ 는 분광 광도 계 제조사에서 제공한 흰색 하부 배경에서 측정한 $\mathrm{L}, \mathrm{a}^{*}$, $\mathrm{b}^{*}$ 을 기준값으로 정했다. 기준값을 바탕으로 지르코니 아 시편은 그대로 두고 나머지 하부 배경을 지르코니아 시편 하방에 위치시켜 같은 방식으로 $\Delta \mathrm{L}, \Delta \mathrm{a}^{*}, \Delta \mathrm{b}^{*}$ 측 정 및 $\Delta \mathrm{E}$ 값을 계산하였다. 이와 같은 방식으로 모든 지 르코니아 시편을 반복 측정하여 각 10 개 시편의 $\Delta \mathrm{E}$ 값의 평균 및 표준편차를 계산하였다.

통계 분석은 SPSS 21.0 (IBM, Chicago, USA)를 사용 하였다. Kolmogorov-Smirnov 검정으로 정규성 검증되 지 않아 통계적 유의성 검증을 위해 비모수 검정을 시행 하였다. 지르코니아 두께, 종류 및 배경에 따른 $\Delta \mathrm{E}$ 값의 유의성을 검증하기 위해 Kruskal-Wallis 검정을 시행하였 다 $(\alpha=0.05)$. 모든 Kruskal-Wallis 검정은 Bonferroni 교 정을 이용하여 사후 검정하였다.

\section{결과}

각 평균 $\Delta \mathrm{E}$ 값을 인지 한계 1.0 및 허용 한계 3.7과 비
교하면, $\mathrm{HP}$ 의 평균 $\Delta \mathrm{E}$ 값은 $\mathrm{A} 1$ 와 $\mathrm{A} 3$ 레진 하부 배경에 서는 모든 두께에서 인지 한계보다 낮은 값을 보였으며, 청색 하부 배경에서 $1.5 \mathrm{~mm}$ 두께 이하에서 인지 한계보 다 높았고 금속 하부 배경에서는 $0.5 \mathrm{~mm}$ 두께에서만 인 지 한계 이상의 값을 보였다. 흰색 하부 배경에서는 1.5 $\mathrm{mm}$, 검정색 하부 배경에서는 $1.0 \mathrm{~mm}$ 두께 이하에서 허 용 한계보다 높았으며 모든 두께에서 인지 한계보다 높 았다(Fig. 4). HW와 FW의 평균 $\Delta \mathrm{E}$ 값은 모든 하부 배경 및 두께에서 인지 한계와 허용 한계보다 높은 $\Delta \mathrm{E}$ 값을 보였다(Fig. 5, 6). 지르코니아 종류, 하부 배경, 두께 변화 에 따른 평균 $\Delta \mathrm{E}$ 값의 유의한 차이가 있었다 $(P<0.05)$ (Table 2).

\section{고찰}

세 가지 다른 종류의 지르코니아 시편의 두께 및 하부 배경의 변화에 따른 색조 차단 효과의 유의한 차이가 있 는지 확인하기 위한 목적으로 실험을 진행하였고, 지르 코니아 종류와 배경 상호 차이에 따른 평균 $\Delta \mathrm{E}$ 값, 지르 코니아 종류 및 하부 배경에 대하여 두께의 차이에 따른 평균 $\Delta \mathrm{E}$ 값의 유의한 차이가 존재하였으므로 귀무 가설 은 기각되었다.

본 연구 결과에 따라 $\mathrm{HP}$ 는 지르코니아는 $\mathrm{A} 1, \mathrm{~A} 3$ 레진 하부 배경에서는 모든 두께에서 색조 차단 효과를 보이 며 청색, 흰색 하부 배경에서는 $1.5 \mathrm{~mm}$, 검정 배경에서는 $1.0 \mathrm{~mm}$ 이상의 두께에서 색조 차단 효과를 보이며 $\mathrm{HW}$ 와 $\mathrm{FW}$ 는 모든 하부 배경과 모든 두께에서 색조 차단 효 과를 보이지 못했다. 본 연구의 색조 차단 효과가 실험 조건에 따라 다양하게 나타나는 이유는 반투명도로 설명 


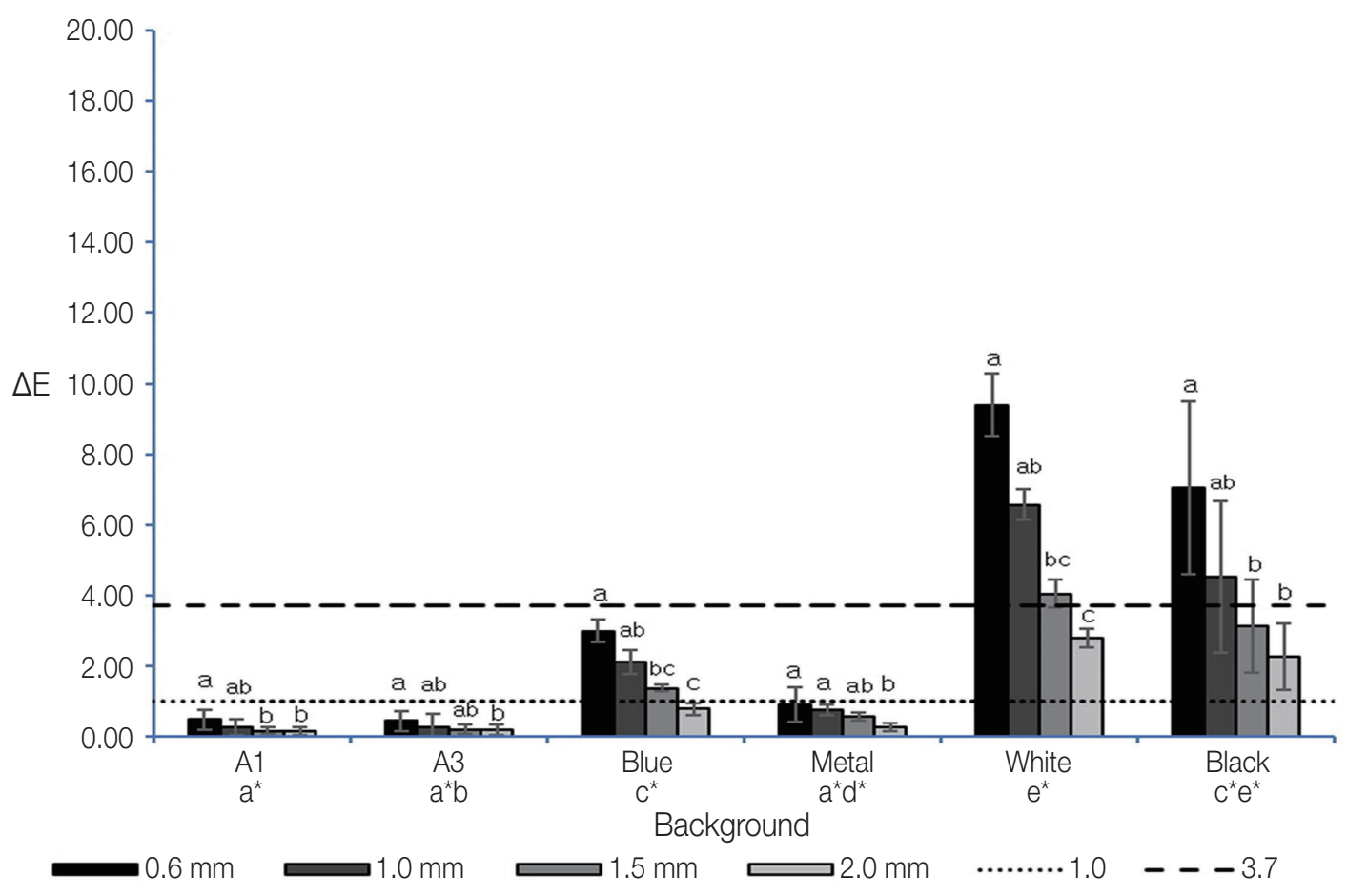

Fig. 4. $\Delta E$ for Ceramill zolid ht+ preshade A2 with other backgrounds based on A2 background at four different thicknesses. Different superscript letters in the same column represent statistically significant diffenrences in the column $(P<0.05)$.

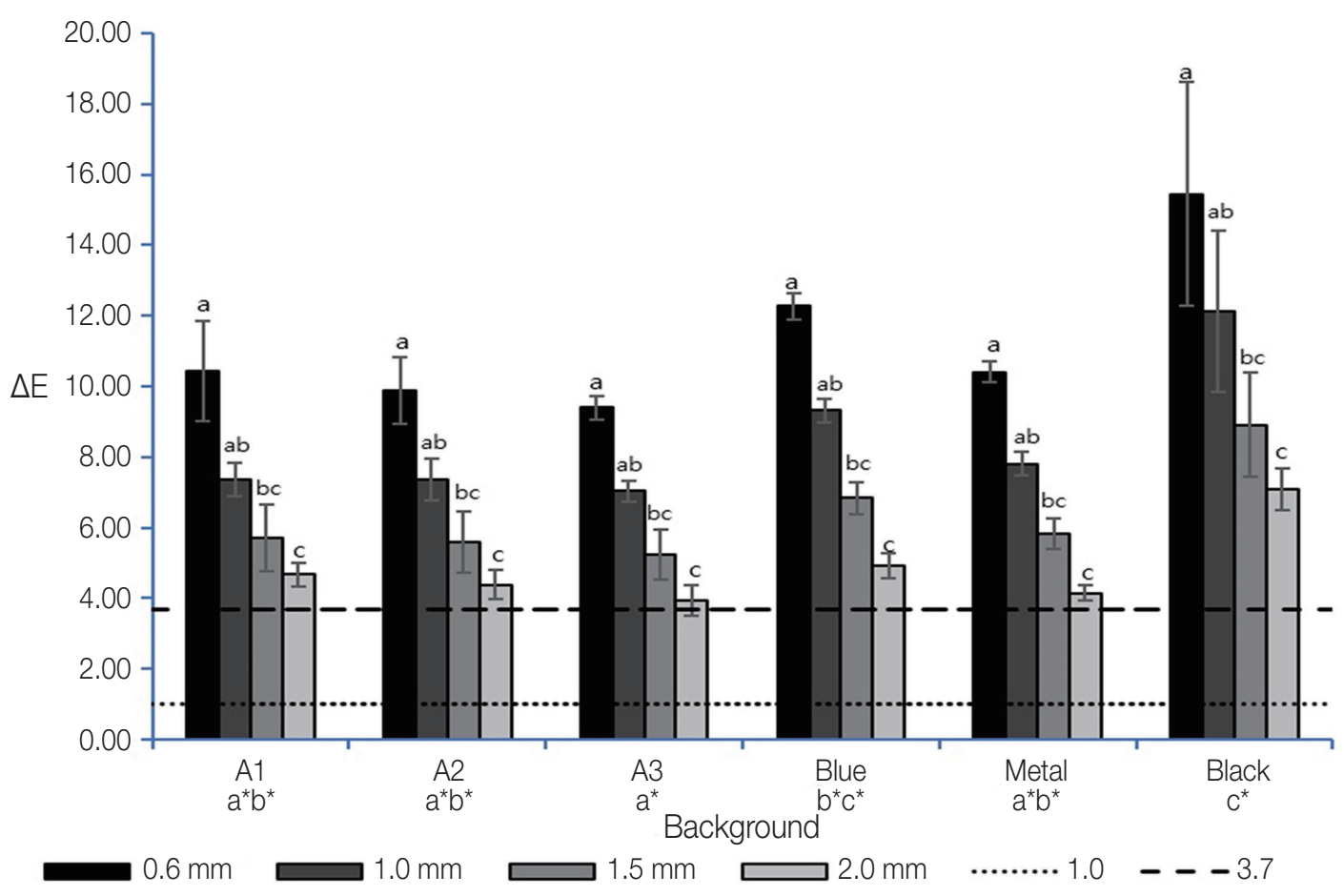

Fig. 5. $\Delta \mathrm{E}$ value for Ceramill zolid ht+ white with other backgrounds based on white background at four different thicknesses. Different superscript letters in the same column represent statistically significant diffenrences in the column $(P<0.05)$. 


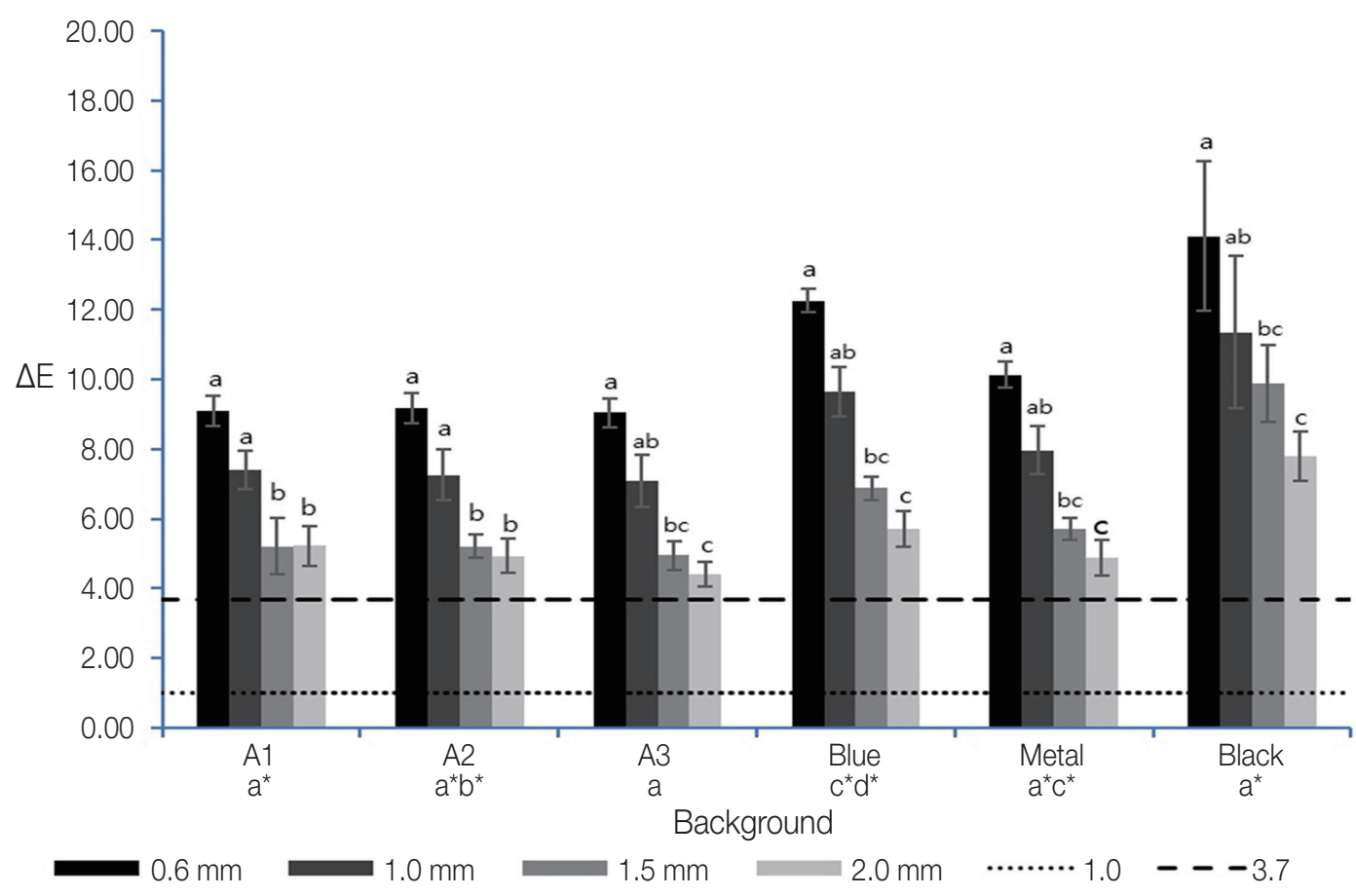

Fig. 6. $\Delta E$ value for Ceramill zolid fx white with other backgrounds based on white background at four different thicknesses. Different superscript letters in the same column represent statistically significant diffenrences in the column $(P<0.05)$.

Table 2. Kruskal-Wallis test with Zirconia Thickness, zirconia shade and background

\begin{tabular}{cccc}
\hline Factor & X2 & Df & $P$-value \\
\hline Thickness & 172.116 & 3 & $0.000^{*}$ \\
Zirconia shade & 256.571 & 1 & $0.000^{*}$ \\
Background & 81.395 & 4 & $0.000^{*}$ \\
\hline
\end{tabular}

The symbol $(*)$ represents statistical significant difference $(P<0.05)$.

할 수 있다. 반투명도는 물체에 조사된 광 중 투과된 광 의 비율을 의미하는 것으로 반투명도가 높다는 것은 투 과되는 광의 비율이 높다는 의미이므로, 물체 하부의 색 조가 발현될 수 있다. ${ }^{8}$ 결과 색조는 따라서 지르코니아와 하부 배경의 색조의 조합으로 설명된다. 지르코니아의 두께 증가에 따라 반투명도가 감소하므로 두께를 증가 시켜 색조 차단 효과를 임상적으로 조절할 수 있다.

도재의 반투명도를 측정하는 방법에는 절대적 투과 도 측정법과 상대적 투과도 측정법이 있다. 절대적 투과 도 측정법은 도재를 통과하는 광의 투과 비율을 측정하 며, 상대적 투과도는 일반적으로 검정색과 흰색 배경에서 의 반사도의 비율을 계산한 대비율(contrast ratio) 또는 검정색과 흰색 배경에서의 색조 차이를 계산한 반투명도 계수(translucency parameter)로 나타낸다. ${ }^{22,23}$ Zadeh 등 ${ }^{24}$ 은 Ceramill zolid fx의 절대적 반투명도가 $38.3 \pm 0.3 \%$ 라고 보고하였다. 본 실험에서 측정한 CIELa*b*에 따라 HW와 $\mathrm{FW}$ 의 반투명도 계수는 검정 하부 배경에서의 $\Delta \mathrm{E}$ 값과 같 은 수치를 나타낸다. 제조사에 따르면 FW의 반투명도가 $\mathrm{HW}$ 의 반투명도보다 상대적으로 $10 \%$ 정도 높다고 표기 하고 있는데, 본 연구에서는 두께 증가에 따라 반투명도 계수가 감소하는 양상을 보이나 $2.0 \mathrm{~mm}$ 두께를 제외하 고 나머지 두께에서는 $\mathrm{HW}$ 와 $\mathrm{FW}$ 의 반투명도 계수의 유 의한 차이는 없었다.

본 연구에서는 $\mathrm{A} 1, \mathrm{~A} 2, \mathrm{~A} 3$ 레진 하부 배경 간에 색조 차단 효과의 유의한 차이는 발견되지 않았다. Tabatabaian 등 ${ }^{21}$ 은 $0.5 \mathrm{~mm}$ 두께의 흰색 지르코니아를 $\mathrm{A} 1, \mathrm{~A} 2$, 
$\mathrm{A} 3, \mathrm{~B} 2, \mathrm{C} 2, \mathrm{D} 3$ 레진 배경하에서 색조 차단 효과를 조사 하였고, 모든 배경 하에서 $\Delta \mathrm{E}$ 값이 인지 한계를 초과하 였고 배경 간에 유의한 차이가 존재한다고 보고하였다. 이는 본 연구와 사용된 지르코니아 종류 및 사용된 레진 종류 등의 차이로 다른 결과를 보인 것으로 추정되며 다 른 색조의 레진을 사용하여 추가적인 실험이 필요하다.

지르코니아 수복물은 자연치 또는 레진뿐 아니라 아 말감, 금합금, 티타늄 등 다양한 수복재 및 지대주 상에 도 수복된다. $\mathrm{Oh}$ 와 $\mathrm{Kim}^{25}$ 은 $\mathrm{A} 2$ 색조의 지르코니아 크라 운의 금합금, 니켈-크롬 합금과 4가지 색조(A1, A2, A3, A4)의 복합 레진 지대주 상에서 지르코니아 최종 색상을 평가했고 금합금이 유의한 색조 차이를 야기한다고 보고 하였다. Tabatabaian 등 의 연구에서는 금색 비귀금속 합 금이 니켈-크롬 합금보다 받아들일만한 색상 변화를 만 들었다. Shimada 등 ${ }^{26}$ 은 올세라믹 크라운이 금합금 지대 주 상에 위치할 때 복합레진 또는 은-팔라듐 합금 지대주 상에서 보다 유의하게 높은 L, a*, b* 값을 보였다. 이는 다른 제조사의 지르코니아 사용, 다른 코핑 두께 및 비니 어 지르코니아 부재가 결과의 차이를 보이는 것으로 설 명된다. 따라서 본 연구에서 사용한 레진 코어, 합금뿐 아 니라 금합금, 티타늄 등 다른 하부 배경과의 비교 연구가 필요하다.

본 연구에서 stain 여부가 HP와 HW의 색조 차단 효과 에 유의한 차이를 보였다. Sen 등 ${ }^{27}$ 은 지르코니아의 착색 과정이 반투명도에 미치는 효과에 대해 조사하였고 일부 종류의 지르코니아에서 유의미한 반투명도 감소를 보였 다고 보고하였다. Spyropoulou 등 ${ }^{28}$ 은 특정 색조 간에 반 투명도의 유의한 차이를 보였다고 보고했다. 많은 지르 코니아 색조 차단 연구에서 $\mathrm{A} 2$ 색조의 지르코니아를 사 용하였는데 다른 색조의 지르코니아를 사용한 색조 차 단 효과의 차이 비교에 대한 추가 연구가 필요하다.

Tabatabaian 등 ${ }^{29}$ 은 $0.4 \mathrm{~mm}$ 부터 $2.0 \mathrm{~mm}$ 까지 $0.2 \mathrm{~mm}$ 간격으로 지르코니아 색조 차단 효과를 연구하였다. $\operatorname{Kim}$ 등 $^{30}$ 은 $1.0 \mathrm{~mm}$ 부터 $0.1 \mathrm{~mm}$ 증가시킨 11 개의 그룹 으로 색조 차단 효과를 조사하였다. 두 실험 모두 본 연 구보다 작은 두께 차이로 군을 나누어 색조 차단 효과를 비교하였고 모두 두께 변화에 따라 유의한 차이가 있는 것으로 보고되었다. 본 연구는 0.4 또는 $0.5 \mathrm{~mm}$ 차이의 다소 넓은 범위로 군을 나누었기 때문에 두께 군을 세분 화한 추가 연구가 필요하다.

지르코니아 코어가 존재하는 임상적 상황에서 불투명 접착제의 사용, 비니어 포세린 두께 증가, 적절한 지르코
니아 코핑 두께를 포함한 배경 색조를 보상하는 선택이 가능하다. ${ }^{31,32}$ Malkondu 등 ${ }^{31}$ 은 $0.6 \mathrm{~mm}, 1.0 \mathrm{~mm}$ 두께의 지르코니아 시편을 GI 접착제, RMGI 접착제, 레진 접착 제를 표면에 적용한 후 $\Delta \mathrm{E}$ 및 반투명도를 측정하였고, 두께가 작을수록 반투명도에 대한 접착제의 영향이 증가 하며 $0.6 \mathrm{~mm}$ 두께의 레진 접착제 군을 제외하고 유의할 만한 색변화는 없었다고 보고하였다. Tabatabaian 등 $^{33}$ 은 $0.5 \mathrm{~mm}$ 지르코니아 세라믹의 4 가지 접착제 적용 여부에 따른 색조 변화를 비교하였고 접착제 종류에 따라 유의 한 색조 차이를 보였다고 보고하였다.

이번 연구에서 각 군의 정규성 검정인 KolmogorovSmirnov 검정 및 Shapiro Wilk 검정의 $P$ 값이 모두 0.05 미만이었기 때문에 통계적 유의성 검증을 위해 정규성 검정인 Repeated Measure ANOVA 대신 비모수 검정인 Kruskal-Wallis 검정을 시행하였다. 각 군 측정값의 정규 성을 만족하지 못한 이유로는 표본이 10 개로 정규성을 충족하기에 적었으며 실험에 사용한 분광 광도계 측정 방식이 외부 광원 등을 완벽히 차단한다고 보기 어려워 측정값의 편차가 커진 것으로 보인다.

치과에서 사용되는 고투명도 지르코니아는 다양한 제 조사에서 생산되고 있으며 본 연구에서는 Amann Gir$\mathrm{rbach}$ 사의 지르코니아만 사용하였다. 이 제조사의 지르 코니아는 투명도에 따라 저투명도(low translucent), 고 투명도(high translucent), 초고투명도(super-high translucent) 세 가지 군으로 분류하며, stain에 따라 white, pre-stained, multilayer로 분류하여 다양한 종류의 지르 코니아가 제조된다는 장점이 있다. 본 연구의 목적인 투 명도와 stain 여부에 따른 지르코니아의 색조 차단 효과 비교를 위해 같은 제조사의 지르코니아를 선택함으로써 결과에 대한 다른 변인의 영향을 최소화하였다.

본 연구의 결과에 따르면 지르코니아 stain 여부에 따 른 색조 차단 효과가 유의하게 차이가 있었으며, 하부 배 경에 따라서도 색조 차단 효과가 유의하게 다르게 나타 났으며 특히 임상적으로 지대치에 청색의 코어 레진으로 수복된 경우 하부 색조가 지르코니아의 최종 색조에 영 향을 줄 수 있음을 주의하여야 한다. 두께에 따라서도 색 조 차단 효과의 유의한 차이를 보였기 때문에 임상적으 로 지르코니아의 두께를 조절하는 것이 색조 차단 효과 에 용이할 것이다. 앞서 언급한 지르코니아 종류, 색조, 두께, 접착제 여부 외에도 제조사, 비니어 세라믹, 소성 과정 등의 색조 차단 효과에 대한 후속 연구가 필요하다. 


\section{결론}

3 종류의 고투명도 지르코니아의 두께와 하부 배경에 따른 색조 차단 효과를 비교하기 위한 본 연구의 한계 내 에서 다음과 같은 결론을 도출하였다. 본 연구에 사용된 3 종류의 고투명도 지르코니아의 평균 $\Delta \mathrm{E}$ 값은 지르코 니아 색조, 하부 배경, 두께 변화에 따라 모두 유의한 차 이를 보였다. $\mathrm{HP}$ 의 색조 차단 효과를 얻기 위해서 청색 하부 배경에서는 $2.0 \mathrm{~mm}$ 이상 두께, 금속 하부 배경에 서는 $1.0 \mathrm{~mm}$ 이상 두께, $\mathrm{A} 1$ 와 A3 레진 하부 배경에서는 $0.5 \mathrm{~mm}$ 이상의 두께가 요구된다. $\mathrm{HW}$ 및 $\mathrm{FW}$ 의 색조 차 단 효과는 두 종류 모두 모든 두께 및 모든 배경에서 얻 을 수 없었다.

\section{Acknowledgements}

This paper was supported by Wonkwang University in 2021 .

\section{ORCID}

Young-Gon Kim https://orcid.org/0000-0003-3065-6476

Ji-Hye Jung https://orcid.org/0000-0003-3322-4011

Hyun-Jun Kong https://orcid.org/0000-0001-9331-3572

Yu-Lee Kim https://orcid.org/0000-0003-1350-5895

\section{References}

1. Raptis NV, Michalakis KX, Hirayama H. Optical behavior of current ceramic systems. Int J Periodontics Restorative Dent 2006;26:31-41.

2. Zarone F, Russo S, Sorrentino R. From porcelainfused-to-metal to zirconia: clinical and experimental considerations. Dent Mater 2011;27:83-96

3. Jeong ID, Bae SY, Kim DY, Kim JH, Kim WC. Translucency of zirconia-based pressable ceramics with different core and veneer thicknesses. J Prosthet Dent 2016;115:768-72.

4. Vichi A, Louca C, Corciolani G, Ferrari M. Color related to ceramic and zirconia restorations: A review. Dent Mater 2011;27:97-108.

5. Heffernan MJ, Aquilino SA, Diaz-Arnold AM, Haselton DR, Stanford CM, Vargas MA. Relative translucency of six all-ceramic systems. Part I: core materials. J Prosthet Dent 2002;88:4-9.

6. Al Ben Ali A, Kang K, Finkelman MD, Zandparsa $R$, Hirayama $H$. The effect of variations in translucency and background on color differences in CAD/CAM lithium disilicate glass ceramics. J Prosthodont 2014;23:213-20.

7. Tabatabaian F, Taghizade F, Namdari M. Effect of coping thickness and background type on the masking ability of a zirconia ceramic. J Prosthet Dent 2018;119:159-65.

8. Brodbelt RH, O'Brien WJ, Fan PL. Translucency of Dental Porcelains. J Dent Res 1980;59:70-5.

9. Wang F, Takahashi H, Iwasaki N. Translucency of dental ceramics with different thicknesses. J Prosthet Dent 2013;110:14-20.

10. Kanchanavasita W, Triwatana P, Suputtamongkol K, Thanapitak A, Chatchaiganan M. Contrast Ratio of Six Zirconia-Based Dental Ceramics. J Prosthodont 2014;23:456-61.

11. Sulaiman TA, Abdulmajeed AA, Donovan TE, Ritter AV, Vallittu PK, Närhi TO, Lassila LV. Optical properties and light irradiance of monolithic zirconia at variable thicknesses. Dent Mater 2015;31: 1180-7.

12. Baldissara P, Llukacej A, Ciocca L, Valandro FL, Scotti R. Translucency of zirconia copings made with different CAD/CAM systems. J Prosthet Dent 2010;104:6-12.

13. Matsuzaki F, Sekine H, Honma S, Takanashi T, Furuya K, Yajima Y, Yoshinari M. Translucency and flexural strength of monolithic translucent zirconia and porcelain-layered zirconia. Dental Mater 2015;34:910-7.

14. Passos L, Linke B, Street A, Torrealba Y. Effect of thickness, translucency, and firing protocol on the masking ability of a CADCAM zirconia-reinforced lithium silicate for different backgrounds. Int J Comput Dent 2019;22:29-38.

15. Spyropoulou PE, Giroux EC, Razzoog ME, Duff RE. Translucency of shaded zirconia core material. J Prosthet Dent 2011;105:304-7.

16. Lim HN, Yu B, Lee YK. Spectroradiometric and spectrophotometric translucency of ceramic materials. J Prosthet Dent 2010;104:239-46. 
17. Lindsey DT, Wee AG. Perceptibility and acceptability of CIELAB color differences in computer-simulated teeth. J Dent 2007;35:593-9.

18. Ishikawa-Nagai S, Yoshida A, Sakai M, Kristiansen J, Da Silva JD. Clinical evaluation of perceptibility of color differences between natural teeth and allceramic crowns. J Dent 2009;37 Suppl 1:e57-63.

19. Douglas RD, Steinhauer TJ, Wee AG. Intraoral determination of the tolerance of dentists for perceptibility and acceptability of shade mismatch. J Prosthet Dent 2007;97:200-8.

20. Khashayar G, Bain PA, Salari S, Dozic A, Kleverlaan CJ, Feilzer AJ. Perceptibility and acceptability thresholds for colour differences in dentistry. J Dent 2014;42:637-44.

21. Tabatabaian F, Shabani S, Namdari M, Sadeghpour $\mathrm{K}$. Masking ability of a zirconia ceramic on composite resin substrate shades. Dent Res J (Isfahan) 2017;14:389-94.

22. Powers JM, Dennison JB, Lepeak PJ. Parameters that affect the color of direct restorative resins. J Dent Res 1978;57:876-80.

23. Johnston WM, Ma T, Kienle BH. Translucency parameter of colorants for maxillofacial prostheses. Int J Prosthodont 1995;8:79-86.

24. Nassary Zadeh P, Lümkemann N, Sener B, Eichberger M, Stawarczyk B. Flexural strength, fracture toughness, and translucency of cubic/tetragonal zirconia materials. J Prosthet Dent 2018;120:94854.

25. Oh SH, Kim SG. Effect of abutment shade, ceramic thickness, and coping type on the final shade of zirconia all-ceramic restorations: in vitro study of color masking ability. J Adv Prosthodont 2015;7: 368-74.

26. Shimada K, Nakazawa M, Kakehashi Y, Matsumura H. Influence of abutment materials on the resultant color of heat-pressed lithium disilicate ceramics. Dent Mater J 2006;25:20-5.

27. Sen N, Sermet IB, Cinar S. Effect of coloring and sintering on the translucency and biaxial strength of monolithic zirconia. J Prosthet Dent 2018;119:308. e1-7.

28. Spyropoulou PE, Giroux EC, Razzoog ME, Duff RE. Translucency of shaded zirconia core material.
J Prosthet Dent 2011;105:304-7.

29. Tabatabaian F, Dalirani S, Namdari M. Effect of Thickness of Zirconia Ceramic on Its Masking Ability: An In Vitro Study. J Prosthodont 2019;28: 666-71.

30. Kim HK, Kim SH, Lee JB, Han JS, Yeo IS, Ha SR. Effect of the amount of thickness reduction on color and translucency of dental monolithic zirconia ceramics. J Adv Prosthodont 2016;8:37-42.

31. Malkondu O, Tinastepe N, Kazazoglu E. Influence of type of cement on the color and translucency of monolithic zirconia. J Prosthet Dent 2016;116:9028.

32. Kürklü D, Azer SS, Yilmaz B, Johnston WM. Porcelain thickness and cement shade effects on the colour and translucency of porcelain veneering materials. J Dent 2013;41:1043-50.

33. Tabatabaian F, Habib Khodaei M, Namdari M, Mahshid M. Effect of cement type on the color attributes of a zirconia ceramic. J Adv Prosthodont 2016;8:449-56. 


\section{고투명도 지르코니아의 두께 및 하부 배경에 따른 색조 차단 효과}

김영곤 전공의, 정지혜 교수, 공현준 임상부교수, 김유리* 교수

원광대학교 치과대학 치과보철학교실

목적: 이 연구의 목적은 고투명도 3종류의 지르코니아의 두께 및 하부 배경에 따른 색조 차단 효과를 비교, 평가하는 것 이다.

연구 재료 및 방법: 3 종류의 고투명도 지르코니아(Ceramill zolid fx white, Ceramill zolid ht+ white, Ceramill zolid ht+ preshade A2)를 각각 CAD/CAM 방식으로 직경 $10 \mathrm{~mm}$ 의 원판 형태의 4가지 두께 $(0.6 \mathrm{~mm}, 1.0 \mathrm{~mm}, 1.5 \mathrm{~mm}, 2.0 \mathrm{~mm})$ 로 10 개씩 시편을 제작하였다. 하부 배경은 직경 $10 \mathrm{~mm}$, 두께 $10 \mathrm{~mm}$ 로 A1, A2, A3 레진 하부 배경, 청색의 코어 레진 하부 배경, Ni-Cr 합금 하부 배경을 제작하였으며, 추가로 분광 광도계 제조사에서 제공하는 검정색 및 흰색 하부 배경을 사용하였다. 지르코니아 시편과 기준 배경을 접착제없이 겹쳐 분광 광도계로 $\mathrm{L}, \mathrm{a}^{*}, \mathrm{~b}^{*}$ 값을 측정하고 다른 하부 배경과 의 $\Delta \mathrm{E}$ 값을 계산하였다. 계산된 평균 $\Delta \mathrm{E}$ 값을 인지 한계 1.0 과 허용 한계 3.7 값을 기준으로 색조 차단 효과를 비교하였 다. 통계적 유의성 검증을 위해 비모수 검정인 Kruskal-Wallis 검정을 시행하였다 $(\alpha=0.05)$.

결과: 지르코니아 종류, 하부 배경 및 두께 변화에 따른 평균 $\Delta \mathrm{E}$ 값의 유의한 차이를 보였다 $(P=0.000)$.

결론: 본 연구 결과에 의하면, 색조를 가지는 고투명도 지르코니아는 청색 레진 코어를 제외한 치아, 복합레진 및 지대주 상에 수복될 때 원하는 지르코니아 색조를 얻을 수 있다.

(구강회복응용과학지 2021;37(4):199-208)

주요어: 지르코니아; 색조 차단; 반투명도; 두께; 하부 배경; 분광 광도법

*교신저자: 김유리

(54538) 전북 익산시 무왕로 895 원광대학교 치과대학병원 2층 치과보철과

Tel: 063-859-2937 || Fax: 063-857-4002 | E-mail: pro11@wku.ac.kr

접수일: 2021년 7월 30일 | 수정일: 2021년 8월 23일 | 채택일: 2021년 10월 2일 